\title{
Phenylketonuria
}

\section{The In Vivo Hydroxylation Rate of Phenylalanine into Tyrosine Is Decreased}

\author{
F.J. van Spronsen, ${ }^{\star}$ D.-J. Reijngoud, ${ }^{\star}$ G.P.A. Smit, ${ }^{\star}$ G.T. Nagel, ${ }^{\ddagger}$ F. Stellaard, ${ }^{\star}$ R. Berger, ${ }^{\S}$ and H.S.A. Heymans \\ ${ }^{*}$ Beatrix Children's Hospital, University Hospital of Groningen, 9700 RB Groningen, The Netherlands; ${ }^{\ddagger}$ Laboratory Center, University \\ Hospital of Groningen, 9700 RB Groningen, The Netherlands; ${ }^{\S}$ Laboratory of Metabolic Diseases, Children's University Hospital of \\ Utrecht, 3501 CA Utrecht, The Netherlands; and Emma Children's Hospital AMC, University of Amsterdam, 1105 AZ Amsterdam, \\ The Netherlands
}

\section{Abstract}

In phenylketonuria (PKU), the enzyme phenylalanine hydroxylase is deficient, resulting in a decreased conversion of phenylalanine (Phe) into tyrosine (Tyr). The severity of the disease is expressed as the tolerance for Phe at $5 \mathrm{yr}$ of age. In PKU patients it is assumed that the decreased conversion of Phe into Tyr is directly correlated with the tolerance for Phe. We investigated this correlation by an in vivo stable isotope study. The in vivo residual hydroxylation was quantitated using a primed continuous infusion of $\mathrm{L}-[$ ring$\left.{ }^{2} \mathrm{H}_{5}\right]$ Phe and $\mathrm{L}-\left[1{ }^{13} \mathrm{C}\right] \mathrm{Tyr}$ and the determination of the isotopic enrichments of L-[ring $\left.{ }^{2} \mathrm{H}_{5}\right] \mathrm{Phe}, \mathrm{L}-\left[\right.$ ring- $\left.{ }^{2} \mathrm{H}_{4}\right] \mathrm{Tyr}$, and $\mathrm{L}-\left[1{ }^{13} \mathrm{C}\right] \mathrm{Tyr}$ in plasma. Previous reports by Thompson and coworkers (Thompson, G.N., and D. Halliday. 1990. J. Clin. Invest. 86:317-322; Thompson, G.N., J.H. Walter, J.V. Leonard, and D. Halliday. 1990. Metabolism. 39:799-807; Treacy, E., J.J. Pitt, K. Seller, G.N. Thompson, S. Ramus, and R.G.H. Cotton. 1996. J. Inherited Metab. Dis. 19:595602), applying the same technique, showed normal in vivo hydroxylation rates of Phe in almost all PKU patients. Therefore, our study was divided up in two parts. First, the method was re-evaluated. Second, the correlation between the in vivo hydroxylation of Phe and the tolerance for Phe was tested in seven classical PKU patients. Very low $(0.13-$ $0.95 \mu \mathrm{mol} / \mathrm{kg}$ per hour) and normal (4.11 and $6.33 \mu \mathrm{mol} / \mathrm{kg}$ per hour) conversion rates were found in patients and controls, respectively. Performing the infusion study twice in the same patient and wash-out studies of the labels at the end of the experiment in a patient and control showed that the method is applicable in PKU patients and gives consistent data. No significant correlation was observed between the in vivo hydroxylation rates and the tolerances. The results of this study, therefore, showed that within the group of patients with classical PKU, the tolerance does not depend on the in vivo hydroxylation. (J. Clin. Invest. 1998. 101:2875-2880.) Key words: diet $\bullet \mathrm{L}-\left[\right.$ ring $\left._{-}{ }^{2} \mathrm{H}_{5}\right]$ phenylalanine $\bullet$ $\mathrm{L}-\left[\right.$ ring $\left.-{ }^{2} \mathrm{H}_{4}\right]$ tyrosine $\bullet \mathrm{L}-\left[1-{ }^{13} \mathrm{C}\right]$ tyrosine

Address correspondence to F.J. van Spronsen, M.D., Ph.D., Beatrix Children's Hospital, University Hospital of Groningen, P.O. Box 30.001, 9700 RB Groningen, The Netherlands. Phone: 31-50-3612470; FAX: 31-50-361-4235.

Received for publication 27 May 1997 and accepted in revised form 9 April 1998

J. Clin. Invest.

(C) The American Society for Clinical Investigation, Inc. 0021-9738/98/06/2875/06 \$2.00

Volume 101, Number 12, June 1998, 2875-2880

http://www.jci.org

\section{Introduction}

Phenylketonuria (PKU; ${ }^{1}$ McKusick 261600) is caused by a deficiency of the hepatic enzyme phenylalanine hydroxylase (PAH; E.C. 1.14.16.1.). As a consequence phenylalanine (Phe) cannot be converted into tyrosine (Tyr; references 1,2 ). Treatment aims at lowering the plasma Phe concentrations by dietary Phe restriction. The individual tolerance for Phe (i.e., the amount of Phe per kilogram body weight a patient can tolerate without achieving plasma Phe concentrations above a certain level) is used to define the severity of the disease $(2,3)$. Based on the tolerance for Phe at $5 \mathrm{yr}$ of age, Güttler and Lou (3) distinguished three phenotypes, i.e., classical PKU, mild PKU, and persistent benign hyperphenylalaninemia (HPA).

It is more or less assumed that the differences in dietary tolerance for Phe are a direct consequence of the differences in individual ability to convert Phe into Tyr in patients with PKU and HPA. Various in vitro and in vivo studies have aimed at estimation of the individual ability to convert Phe into Tyr (4-7). The measurement of the in vitro enzyme activity, however, necessitates a liver biopsy. Treacy et al. (7), measuring the in vivo oxidation of Phe by use of an oral dose of L- $\left[1-{ }^{13} \mathrm{C}\right] \mathrm{Phe}$, show no clear correlation between the in vivo hydroxylation of Phe and the dietary tolerance for Phe within a specific class of $\mathrm{PAH}$-deficient patients. As with most in vivo methods, however, this method is hampered by problems with quantitating the hydroxylation rate of Phe into Tyr (7).

With the method introduced by Clarke and Bier (8) real quantitation of the in vivo conversion rate of Phe into Tyr has become possible. This method is based on continuous infusion of the stable isotopically labeled tracers L- $\left[\right.$ ring $\left.{ }_{-}^{2} \mathrm{H}_{5}\right] \mathrm{Phe}$ and $\mathrm{L}-\left[1-{ }^{13} \mathrm{C}\right] \mathrm{Tyr}$, and shows consistent results in controls $(8,9)$.

Thompson and coworkers (9-11) applied a primed-continuous infusion technique of the stable isotopically labeled tracers L- $\left[\right.$ ring $\left.^{2}{ }^{2} \mathrm{H}_{5}\right]$ Phe, and L- $\left[3,5-{ }^{2} \mathrm{H}_{2}\right]$ Tyr in PKU and HPA patients. They calculated normal in vivo hydroxylation rates of Phe in 14 out of the 16 PKU patients in three successive studies, and no difference between the PKU and two HPA patients (9-11). These findings are at odds with all other in vitro and in vivo studies (4-7). Because of this highly unexpected observation, their data cast doubt upon the applicability of this primed-continuous infusion technique of stable isotopically labeled tracers of Phe and Tyr in PKU patients. Consequently, their data can not be included without hesitation in a study of relationship between the tolerance for Phe and the in vivo hydroxylation rate of Phe.

Therefore, the aim of this study was to answer two ques-

1. Abbreviations used in this paper: HPA, hyperphenylalaninemia; $\mathrm{PAH}$, phenylalanine hydroxylase; Phe, phenylalanine; PKU, phenylketonuria; Tyr, tyrosine. 
tions in classical PKU patients using the primed-continuous infusion technique of the stable isotopically labeled tracers $\mathrm{L}-\left[\right.$ ring $\left.-{ }^{2} \mathrm{H}_{5}\right] \mathrm{Phe}$, and L- $\left[1-{ }^{13} \mathrm{C}\right] \mathrm{Tyr}$. First, is it possible to calculate the in vivo hydroxylation rate of Phe from the isotopic enrichments in plasma during a primed continuous infusion protocol? Second, is there a correlation between the calculated in vivo hydroxylation of Phe into Tyr and the dietary tolerance for Phe in patients with classical PKU? The patients included in this study had dietary tolerances for Phe pointing at different severities within classical PKU.

\section{Methods}

\section{Subjects}

The studies were approved by the medical ethical committee of the University Hospital of Groningen. Informed consent was obtained from the individuals and/or their parents. Investigations were performed in two adult controls and seven patients. Patient 7 was investigated twice at different starting plasma Phe concentrations. The individual clinical details of the subjects are given in Table I. At the time of the tests all patients were free from intercurrent disease.

Patients were young with the exception of patient 7 who was $20 \mathrm{yr}$ of age when he was studied for the second time. Diagnosis was based on the results of the neonatal screening and the classification according to Güttler and Lou (3). This classification divides between three phenotypes on the basis of the tolerance for Phe at $5 \mathrm{yr}$ of age: classical PKU (tolerance $<20 \mathrm{mg} / \mathrm{kg}$ body weight per day), mild PKU (tolerance $20-50 \mathrm{mg} / \mathrm{kg}$ body weight per day), and persistent benign HPA (tolerance $>70 \mathrm{mg} / \mathrm{kg}$ body weight per day). The tolerances of Phe at $5 \mathrm{yr}$ of age in the patients varied between 11 and $21 \mathrm{mg} / \mathrm{kg}$ body weight per day (Table I). Following the classification of Güttler and Lou (3) all but patient 1 clearly had the classical form of PKU. Patient 1 had a milder form of PKU. The same patient, however, has the classical form of PKU when the guidelines of the original study of Güttler are followed (12).

All patients were on a strict dietary treatment resulting in plasma Phe concentrations within the aimed range according to the therapeutic guidelines of Güttler and Lou at that time (3). The age- and sex-adjusted height for all patients was between the 10th and 90th percentile except for two patients, who had a height just below the

Table I. The Clinical and Metabolic Details of Both PKU Patients and Healthy Individuals

\begin{tabular}{|c|c|c|c|c|c|c|}
\hline \multirow{2}{*}{$\begin{array}{l}\text { Patient } \mathrm{Nr} \\
\text { test }\end{array}$} & \multirow{2}{*}{$\begin{array}{l}\text { Age } \\
\text { at }\end{array}$} & \multirow[b]{2}{*}{ Body wt } & \multicolumn{2}{|c|}{$\begin{array}{l}\text { Tolerance of } \\
\text { phenylalanine }\end{array}$} & \multicolumn{2}{|c|}{$\begin{array}{l}\text { Plasma concentrations } \\
\text { at the start of the test }\end{array}$} \\
\hline & & & $5 \mathrm{yr}$ & Test & Phenylalanine & Tyrosine \\
\hline & $y r$ & $\mathrm{~kg}$ & \multicolumn{2}{|c|}{$m g / k g B W$} & $\mu \mathrm{mol} / \mathrm{l}$ & $\mu \mathrm{mol} / \mathrm{l}$ \\
\hline 1 & 5 & 18 & 21 & 28 & 290 & 180 \\
\hline 2 & 9 & 33 & 17 & 12 & 140 & 40 \\
\hline 3 & 15 & 84 & 19 & 10 & 240 & 30 \\
\hline 4 & 8 & 22 & 15 & 9 & 590 & 20 \\
\hline 5 & 8 & 27 & 15 & 12 & 450 & 10 \\
\hline 6 & 13 & 55 & 16 & 7 & 850 & 30 \\
\hline $7 a$ & 18 & 48 & 11 & 10 & 290 & 40 \\
\hline $\mathrm{b}$ & 20 & 49 & 11 & 10 & 500 & 20 \\
\hline Range & $5-20$ & $18-84$ & $11-21$ & $7-28$ & $140-850$ & 10-180 \\
\hline \multicolumn{7}{|l|}{ Controls } \\
\hline 1 & 44 & 63 & - & - & 42 & 28 \\
\hline 2 & 33 & 68 & - & - & 50 & 40 \\
\hline
\end{tabular}

3rd percentile. The weight to height was between the 50th and the 90th percentile of the Dutch standards (13).

\section{Measurement of hydroxylation rates}

Isotopes. $\mathrm{L}-\left[\right.$ ring- $\left.{ }^{2} \mathrm{H}_{5}\right] \mathrm{Phe}\left(98 \%{ }^{2} \mathrm{H}_{5}\right)$, L- $\left[\right.$ ring- $\left.{ }^{2} \mathrm{H}_{4}\right] \mathrm{Tyr}\left(98 \%{ }^{2} \mathrm{H}_{4}\right)$, and $\mathrm{L}-\left[1-{ }^{13} \mathrm{C}\right] \mathrm{Tyr}\left(98 \%{ }^{13} \mathrm{C}\right)$ were obtained from Cambridge Isotopes Laboratories (Andover, MA). Isotopes were infused in a solution of normal saline that was shown to be sterile and pyrogen free.

Procedure. Blood samples were taken $2-4 \mathrm{~d}$ before the test to calculate the amount of isotopes to be given in the priming doses. Controls were checked for heterozygosity of the PAH gene by measuring the Phe/Tyr ratio. The investigations were carried out in the metabolic ward of the Beatrix Children's Hospital and were started after an overnight fast. The study procedure closely resembled the procedure followed by Thompson et al. (9). During the test, the subjects received no food nor drink except for water. Before the test, two indwelling catheters were placed in the left and right brachial vein for infusion of the stable isotopes and blood sampling. The second catheter was kept open by an infusion of isotonic saline.

After collection of three baseline blood samples at time $=-20$, -10 , and $0 \mathrm{~min}$, subjects received a priming dose of $\mathrm{L}-\left[\right.$ ring $\left._{-}{ }^{2} \mathrm{H}_{5}\right] \mathrm{Phe}$ (patients according equation 1, controls $2.9 \mu \mathrm{mol} / \mathrm{kg}$ ) at time $=0 \mathrm{~min}$, followed by a tracer dose (mean $4.33 \pm 0.09 \mu \mathrm{mol} / \mathrm{kg}$ per hour, $n=8$, SEM) during a total of $6 \mathrm{~h}$, and a priming dose of $\mathrm{L}-\left[1-{ }^{13} \mathrm{C}\right]$ Tyr $(2.7$ $\mu \mathrm{mol} / \mathrm{kg}$ ) at time $=60 \mathrm{~min}$, followed by a continuous infusion of tracer (mean $4.20 \pm 0.24 \mu \mathrm{mol} / \mathrm{kg}$ per hour, $n=8$, SEM) for $5 \mathrm{~h}$. Controls also received a priming dose of L- $\left[\right.$ ring $\left.{ }^{2} \mathrm{H}_{4}\right] \mathrm{Tyr}(0.43 \mu \mathrm{mol} / \mathrm{kg})$ at time $=0 \mathrm{~min}$.

The priming dose $P$ (in milligrams) of L- $\left[\right.$ ring $\left._{-}{ }^{2} \mathrm{H}_{5}\right] \mathrm{Phe}$ for patients was calculated exactly as described by Thompson and Halliday (9) according to equation 1 :

$P=\frac{[F] \times 0.5 \times B W}{100}$

EQUATION 1

in which $[F]$ is the Phe concentration in plasma in micromole per liter and $B W$ is the body weight in kilograms. The factor 0.5 stands for the tracer infusion rate, since Thompson and Halliday infused $0.5 \mathrm{mg} / \mathrm{kg}$ per L- $\left[\right.$ ring $\left._{-}{ }^{2} \mathrm{H}_{5}\right]$ Phe (9). This formula can be derived from the formula for the priming dose given by Wolfe (14). For the priming of the pool, the following equation 2 was derived (14):

$P_{w}=\frac{[F] \times i_{2 H 5 F} \times V}{R_{a F}}$

EQUATION 2

in which $P_{w}$ is the priming dose of L- $\left[\right.$ ring $\left.{ }^{2} \mathrm{H}_{5}\right] \mathrm{Phe}$ in micromole per kilogram according to Wolfe, $i_{2 H 5 F}$ is the $\mathrm{L}-\left[\right.$ ring- $\left.{ }^{2} \mathrm{H}_{5}\right]$ Phe infusion rate in micromole per kilogram per hour, $V$ is the volume of distribution of Phe in liters per kilogram and $\mathrm{R}_{\mathrm{aF}}$ the rate of appearance of Phe in micromole per kilogram per hour.

$P$ can be converted into $P_{w}$ according to equation 3:

$P=P_{w} \times B W \times \frac{165}{1000}$

EQUATION 3

in which 165 is the molecular weight of Phe and 1,000 the conversion factor of micrograms into milligrams. Substituting equation 2 into equation 3, replacing the volume of distribution $V$ with the value of $0.61 \mathrm{l} / \mathrm{kg}$, and $R_{a F}$ with a value of $10 \mathrm{mg} / \mathrm{kg}$ per hour results in equation 1 after some simple arithmetic.

\section{Collection and analysis of samples}

Blood samples were collected into heparinized tubes at 30-min intervals between 2 and $4 \mathrm{~h}$ and at 15-min intervals in the last $2 \mathrm{~h}$ of the studies. The total test procedure amounted to $6.5 \mathrm{~h}$. Blood samples were immediately centrifuged for 5 minutes at $1,000 \mathrm{~g}$. Plasma was stored at $-20^{\circ} \mathrm{C}$ until analyzed.

For isotopic analysis, $\mathrm{L}-\left[\right.$ ring $\left.-{ }^{2} \mathrm{H}_{5}\right] \mathrm{Phe}, \mathrm{L}-\left[\right.$ ring $\left._{-}{ }^{2} \mathrm{H}_{4}\right] \mathrm{Tyr}$, and L-[1$\left.{ }^{13} \mathrm{C}\right] \mathrm{Tyr}$ were derived to their corresponding $N$-acetyl, $O$-penta-fluoro-benzyl ester $(15)$. Plasma $(250 \mu \mathrm{l})$ was deproteinized and devoid 
of anionic compounds by addition of $\mathrm{HCl}(0.1 \mathrm{~N})$ and extracted twice with ethylacetate. The lower layers (water phase) were collected in a clean tube. To these collected layers a phosphate buffer $\left(\mathrm{K}_{2} \mathrm{HPO}_{4}-\right.$ $\mathrm{H}_{3} \mathrm{PO}_{4} 3 \mathrm{M}, \mathrm{pH} 8.5$ ) was added to a final $\mathrm{pH}$ of above 7. The amino acids were $N$-acetylated by the addition of acetic anhydrid under continuous vigorous agitation. Subsequently, the solution was brought to a pH of 3.0 by addition of $\mathrm{HCl}(6 \mathrm{~N})$. The $N$-acetyl derivatives formed were extracted twice with ethylacetate. The upper layers (ethylacetate phase) were collected and evaporated to dryness under a gentle stream of nitrogen at $60^{\circ} \mathrm{C}$. The pento-fluoro-benzyl esters were prepared by adding in sequence $5 \mu \mathrm{l}$ PFB-Br, $10 \mu \mathrm{l}$ triethylamine, and $50 \mu \mathrm{l}$ acetonitril. The derivative was washed with acidic ethylacetate. The ethylacetate layer was evaporated to dryness under a gentle stream of nitrogen at room temperature and to the residue ethylacetate was added.

Plasma L- $\left[\right.$ ring $\left.-{ }^{2} \mathrm{H}_{5}\right] \mathrm{Phe}$ and $\mathrm{L}-\left[1-{ }^{13} \mathrm{C}\right] \mathrm{Tyr}$ isotope enrichments were measured with a Hewlett-Packard Model 5890 gas chromatograph (Amstelveen, The Netherlands) coupled to a VG Trio-II quadrupole mass spectrometer (Fisons, Manchester, United Kingdom). Electron capture negative ion ammonia chemical ionization was used. The analysis of L-Phe and L-Tyr was carried out on a CPSIL 5CB capillary fused silica column (Chrompack, Middelburg, The Netherlands), temperature programmed from $100^{\circ} \mathrm{C}$ to $275^{\circ} \mathrm{C}$ at $25^{\circ} \mathrm{C}$ minutes ${ }^{-1}$. L- $\left[\right.$ ring $\left._{-}{ }^{2} \mathrm{H}_{5}\right]$ Phe eluted at $6.2 \mathrm{~min}$ and $\mathrm{L}-\left[1{ }^{-13} \mathrm{C}\right] \mathrm{Tyr}$ at 7.0 $\mathrm{min}$. Phe was monitored at its base peak m/z 206 [M-167] ${ }^{-}$and its ${ }^{2} \mathrm{H}_{5}$ labeled species at m/z 211, Tyr at its base peak m/z 264 [M-181] $]^{-}$, and its ${ }^{13} \mathrm{C}$-labeled species at $\mathrm{m} / \mathrm{z} 265$.

$\mathrm{L}-\left[\right.$ ring- $\left.{ }^{2} \mathrm{H}_{4}\right]$ Tyr plasma enrichment was measured with a HewlettPackard Model 5890 gas chromatograph coupled to a VG Analytical 70-250 S magnet sector mass spectrometer (Fisons). Electron impact ionization at $70 \mathrm{eV}$ was used. The gas chromatography programming was operated as described above. L-Tyr eluted at $7.3 \mathrm{~min}$ and was monitored at its base peak m/z $344[\mathrm{M}-101]^{+}$and its L-labeled species at $\mathrm{m} / \mathrm{z} 348$.

Plasma enrichments of L- $\left[\right.$ ring $\left._{-}{ }^{2} \mathrm{H}_{5}\right] \mathrm{Phe}, \mathrm{L}-\left[\right.$ ring $\left._{-}{ }^{2} \mathrm{H}_{4}\right] \mathrm{Tyr}$, and L-[1$\left.{ }^{13} \mathrm{C}\right] \mathrm{Tyr}$ were calculated from the intensity ratios of the labeled over unlabeled species using calibration curves. These curves were prepared from standard mixtures of weight amounts of labeled and unlabeled Phe and Tyr ranging from 0 to $10 \%$ mole fraction for $\mathrm{L}-\left[\right.$ ring- $\left.{ }^{2} \mathrm{H}_{5}\right] \mathrm{Phe}$ and $\mathrm{L}-\left[1-{ }^{13} \mathrm{C}\right] \mathrm{Tyr}$, and from 0 to $0.1 \%$ mole fraction for $\mathrm{L}-[$ ring$\left.{ }^{2} \mathrm{H}_{4}\right]$ Tyr when PKU patients were studied, and from 0 to $1 \%$ for controls.

\section{Tracer model for phenylalanine and tyrosine kinetics}

We used the model for Phe-Tyr metabolism as described by Clarke and Bier (8), with modifications as proposed by Thompson and Halliday (9). Briefly the flux of Tyr through the plasma compartment was calculated according to equation 4 :

$Q_{Y}=i_{C Y}\left(\frac{E_{I}}{E_{C Y}}-1\right)$

EQUATION 4

where $i_{C Y}$ is the rate of $\mathrm{L}-\left[1-{ }^{13} \mathrm{C}\right] \mathrm{Tyr}$ infusion (micromole per kilograms per hour) and $E_{i}$ and $E_{c y}$ are the enrichments in mole percent excess of the infusate and plasma $\left[1-{ }^{13} \mathrm{C}\right] \mathrm{Tyr}$, respectively.

The rate of conversion of Phe $(F)$ into Tyr $(Y)\left(Q_{F} \rightarrow\right.$; micromole per kilograms per hour) was derived according to equation 5 :

$Q_{F \rightarrow Y}=Q_{Y} \frac{E_{D Y}}{E_{F}}$

EQUATION 5

where $Q_{Y}$ is the Tyr flux through the plasma compartment, and $E_{D Y}$ and $E_{F}$ are the plasma enrichments of L- $\left[\right.$ ring $\left.{ }^{2} \mathrm{H}_{4}\right] \mathrm{Tyr}$ and L-[ring${ }^{2} \mathrm{H}_{5}$ ]Phe.

Calculation of the hydroxylation rate of Phe into Tyr is based on the use of the isotopes L- $\left[\right.$ ring $\left._{-}{ }^{2} \mathrm{H}_{5}\right] \mathrm{Phe}$ and $\mathrm{L}-\left[1-{ }^{13} \mathrm{C}\right] \mathrm{Tyr}$, and the model of the Phe-Tyr metabolism as summarized in equation 5. In equation 5 , it is assumed that there are no isotope effects and that the enrichment in plasma is similar to that in cytosol of the liver cells.
These assumptions about the isotope effect were recently under investigation (16-18). In general it appeared that these assumptions do not hold under all conditions. In our study, however, we compared the hydroxylation rate of patients and controls and compared them to literature data, in which the same methodology and isotopes were used giving differences in isotopes and intracellular dilution.

Plasma Phe and Tyr concentrations were determined in plasma using an ion exchange liquid chromatography amino acid analyzer (Carlo Erba 3A30; Interscience, Breda, The Netherlands). In our laboratory modifications resulted in a coefficient of variation of this method of $2 \%$.

Statistical analyses were performed using the Student's $t$ test for testing the statistical significance of the difference in hydroxylation rates between controls and patients and within the studied group of patients. We used the Kendall's ranking correlation test for testing the statistical significance of a correlation between the tolerance for Phe at $5 \mathrm{yr}$ of age and the in vivo hydroxylation rate.

\section{Results}

In all patients plateau plasma enrichments were achieved for both L- $\left[\right.$ ring $\left._{-}{ }^{2} \mathrm{H}_{5}\right] \mathrm{Phe}, \mathrm{L}-\left[1-{ }^{13} \mathrm{C}\right] \mathrm{Tyr}$, and L- $\left[\right.$ ring $\left._{-}{ }^{2} \mathrm{H}_{4}\right] \mathrm{Tyr}$ in $<2 \mathrm{~h}$. In Fig. $1, A-C$, the mean plasma enrichments are presented for $\mathrm{L}-\left[\right.$ ring $\left.-{ }^{2} \mathrm{H}_{5}\right] \mathrm{Phe}, \mathrm{L}-\left[1-{ }^{13} \mathrm{C}\right] \mathrm{Tyr}$, and $\mathrm{L}-\left[\right.$ ring- $\left.{ }^{2} \mathrm{H}_{4}\right] \mathrm{Tyr}$, respectively.

In the controls plateau enrichment was achieved in $<2 \mathrm{~h}$ for all isotopes but $\mathrm{L}-\left[\right.$ ring- $\left.{ }^{2} \mathrm{H}_{4}\right] \mathrm{Tyr}$ (results not shown). The enrichments of L- $\left[\right.$ ring $\left._{-}{ }^{2} \mathrm{H}_{5}\right] \mathrm{Phe}$ and $\mathrm{L}-\left[\right.$ ring- $\left.{ }^{2} \mathrm{H}_{4}\right] \mathrm{Tyr}$ in controls (Table II) were similar to those reported previously $(8-10,16$, 17). The enrichments of L-[1- $\left.{ }^{13} \mathrm{C}\right] \mathrm{Tyr}$ in controls and patients were twice as high as reported in controls by others $(8,16)$ because of higher infusion rates in our study protocol. The enrichments of L- $\left[\right.$ ring $\left.^{2}{ }^{2} \mathrm{H}_{4}\right]$ Tyr in our patients were extremely low if compared with controls in this study and other studies

Table II. The Individual Mean Isotopic Enrichments of L-[ring- $\left.{ }^{2} \mathrm{H}_{5}\right]$ Phe, $L$-[ring $\left.{ }^{2} \mathrm{H}_{4}\right] T y$ r, and $L-\left[1-{ }^{13} \mathrm{C}\right] \mathrm{Tyr}$, as well as the Flux of Tyrosine and the Hydroxylation of Phenylalanine in Seven PKU Patients and Two Healthy Adult Individuals

\begin{tabular}{|c|c|c|c|c|c|}
\hline \multirow[b]{2}{*}{ Patient nr } & \multicolumn{3}{|c|}{$\begin{array}{c}\text { Plasma enrichments* of phenylalanine } \\
\text { and tyrosine }\end{array}$} & \multirow[b]{2}{*}{$\begin{array}{c}\text { Tyrosine } \\
\text { flux }^{\ddagger}\end{array}$} & \multirow[b]{2}{*}{$\begin{array}{l}\text { Phenylalanine } \\
\text { hydroxylation }\end{array}$} \\
\hline & $\begin{array}{l}{\left[{ }^{2} \mathrm{H}_{5}\right] \text { Phenyl- }} \\
\text { alanine }\end{array}$ & $\begin{array}{l}{\left[{ }^{13} \mathrm{C}\right] \text { Tyro- }} \\
\text { sine }\end{array}$ & $\begin{array}{l}{\left[{ }^{2} \mathrm{H}_{4}\right] \text { Tyro- }} \\
\text { sine }\end{array}$ & & \\
\hline 1 & 5.82 & 16.16 & 0.106 & 19.0 & 0.35 \\
\hline 2 & 7.33 & 12.95 & 0.036 & 26.9 & 0.13 \\
\hline 3 & 6.54 & 10.55 & 0.029 & 37.6 & 0.17 \\
\hline 4 & 11.09 & 6.94 & 0.028 & 64.5 & 0.16 \\
\hline 5 & 4.68 & 7.58 & 0.083 & 53.7 & 0.95 \\
\hline 6 & 11.50 & 5.21 & 0.110 & 80.4 & 0.77 \\
\hline $7 a$ & 5.27 & 8.13 & 0.047 & 37.6 & 0.34 \\
\hline $\mathrm{b}$ & 5.34 & 13.62 & 0.033 & 24.0 & 0.15 \\
\hline Mean & 7.20 & 10.14 & 0.059 & 43.0 & 0.38 \\
\hline SD & 0.94 & 1.35 & 0.012 & 7.6 & 0.11 \\
\hline \multicolumn{6}{|l|}{ Controls } \\
\hline \multicolumn{6}{|l|}{$\mathrm{nr}$} \\
\hline 1 & 8.91 & 9.71 & 1.48 & 41.4 & 6.33 \\
\hline 2 & 9.86 & 11.68 & 1.69 & 33.6 & 4.11 \\
\hline
\end{tabular}

*Mole percent excess; ${ }^{*} \mu \mathrm{mol} / \mathrm{kg} / \mathrm{hr}$. 

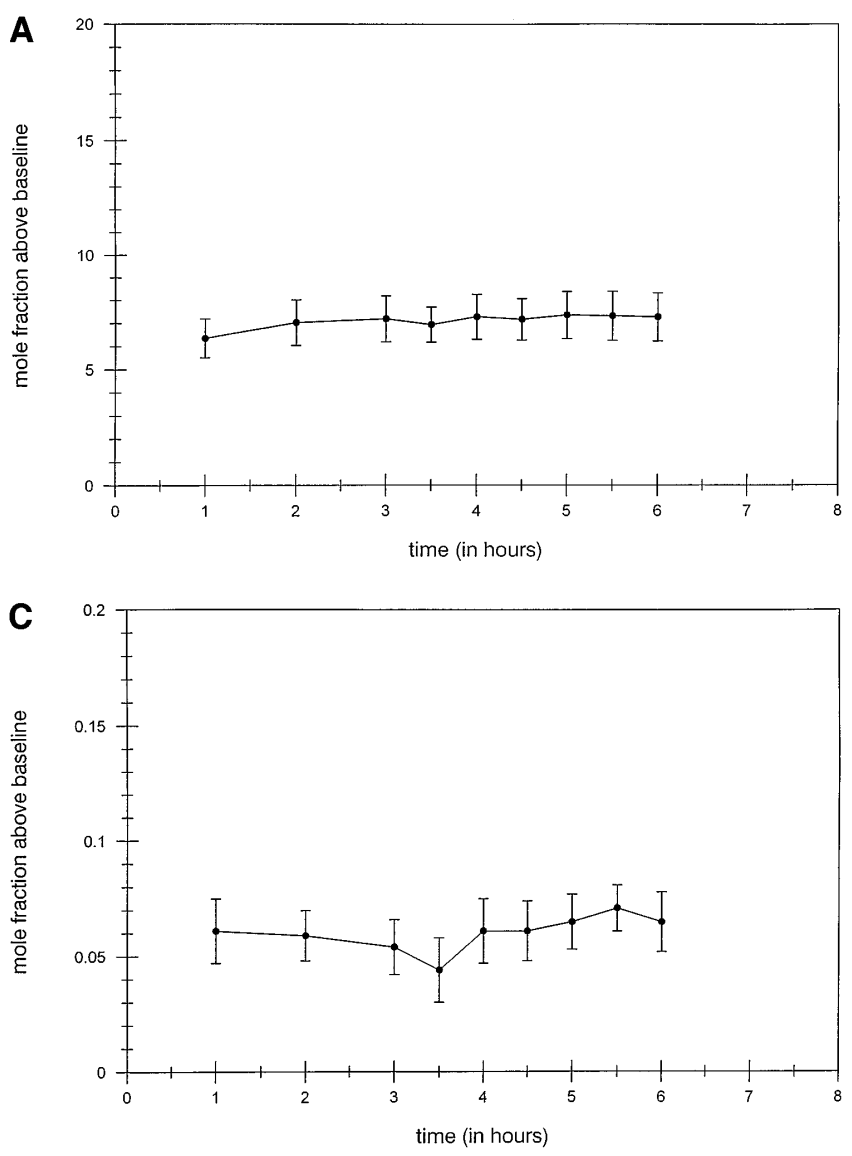

$(8-10,16,17)$, as well as patients studied by two of the studies of Thompson et al. $(9,10)$, while no information was given in a third study (11).

Following the analytical methods of Thompson and Halliday (9) using an electron-impact ionization on a quadrupole mass spectrometer (9), reliable measurements of the enrichment of L- $\left[\right.$ ring $\left.-{ }^{2} \mathrm{H}_{4}\right]$ Tyr were not possible. This was caused by a combination of the very low enrichment of the tracer and a high level of background noise due to unknown compounds that could not be resolved from the Tyr peak by this method. We, therefore, had to refine the analytical methods for isotopic analyses of L- $\left[\right.$ ring $\left.-{ }^{2} \mathrm{H}_{4}\right] \mathrm{Tyr}$. After trying several other methods, the samples were derivatized to their corresponding $\mathrm{N}$-acetyl, $\mathrm{O}$-penta-fluoro-benzyl ester, following the analytical methods of de Jong et al. (15). This way we could obtain a reproducible and quantitatable signal with a sector magnet instrument in electron impact ionization mode, resulting in reliable measurements of the enrichment of L- $\left[\right.$ ring $\left._{-}{ }^{2} \mathrm{H}_{4}\right] \mathrm{Tyr}$.

To further determine the appropriateness of the measurements of L- $\left[\right.$ ring $\left._{-}{ }^{2} \mathrm{H}_{4}\right] \mathrm{Tyr}$, we determined the extent of wash out of label $30 \mathrm{~min}$ after the infusion of isotopes had been stopped in a patient and control. In the patient the mole percent enrichments of L- $\left[\right.$ ring- $\left.{ }^{2} \mathrm{H}_{5}\right] \mathrm{Phe}, \mathrm{L}-\left[1-{ }^{13} \mathrm{C}\right] \mathrm{Tyr}$, and $\mathrm{L}-[$ ring$\left.{ }^{2} \mathrm{H}_{4}\right] \mathrm{Tyr}$ decreased from 4.3 to $3.9 \%$, from 4.7 to $2.0 \%$, and from 0.042 to $0.038 \%$, respectively. In the control these values decreased from 5.7 to $1.4 \%$, from 3.9 to $1.3 \%$, and from 0.78 to $0.42 \%$, respectively. In both the patient and control, the decrease of the enrichment of L- $\left[1-{ }^{13} \mathrm{C}\right] \mathrm{Tyr}$ was of the same mag-

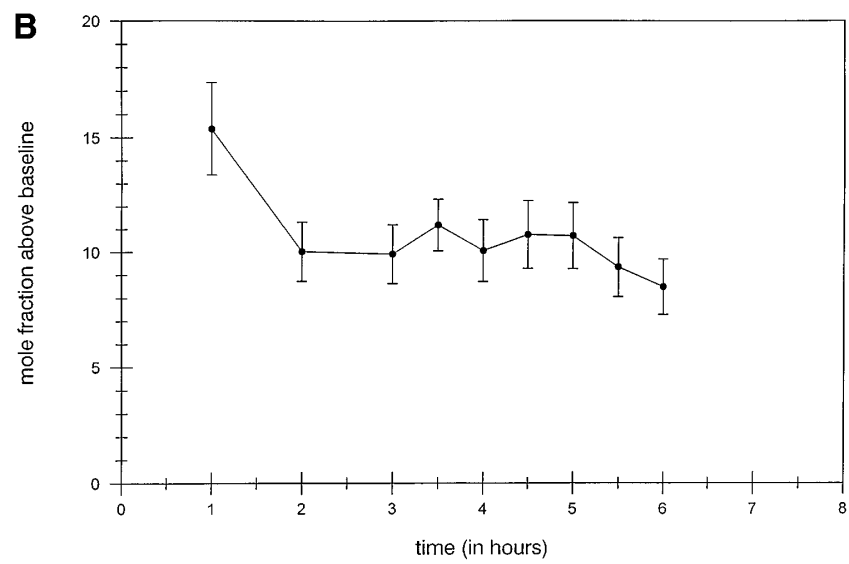

Figure 1. (A) Mean isotopic enrichments of $\mathrm{L}-\left[\operatorname{ring}_{-}{ }^{2} \mathrm{H}_{5}\right] \mathrm{Phe}$ in $\mathrm{PKU}$ patients with one SEM at different moments during the test with simultaneous infusion of L- $\left[\right.$ ring $\left.-{ }^{2} \mathrm{H}_{5}\right]$ Phe and L- $\left[1-{ }^{13} \mathrm{C}\right]$ tyrosine. $(B)$ Mean isotopic enrichments of $\mathrm{L}-\left[1-{ }^{13} \mathrm{C}\right]$ tyrosine in PKU patients with one SEM at different moments during the test with simultaneous infusion of L- $\left[\right.$ ring- $\left.{ }^{2} \mathrm{H}_{5}\right]$ Phe and L- $\left[1-{ }^{13} \mathrm{C}\right] \mathrm{Tyr}$. $(C)$ Mean isotopic enrichments of $\mathrm{L}-\left[\right.$ ring $\left.{ }_{-}^{2} \mathrm{H}_{4}\right] \mathrm{Tyr}$ in PKU patients with one SEM at different moments during the test with simultaneous infusion of L- $\left[\right.$ ring- $\left.^{2} \mathrm{H}_{5}\right] \mathrm{Phe}$ and $\mathrm{L}-\left[1-{ }^{13} \mathrm{C}\right]$ Tyr.

nitude. The similarity of the decreases of the enrichments of L- $\left[\right.$ ring $\left.-{ }^{2} \mathrm{H}_{5}\right] \mathrm{Phe}$ and $\mathrm{L}-\left[\right.$ ring $\left.{ }^{2} \mathrm{H}_{4}\right]$ Tyr in the PKU patient suggests a precursor-product relationship between the metabolites indicating that we indeed measured L- $\left[\right.$ ring $\left.{ }_{-}^{2} \mathrm{H}_{4}\right] \mathrm{Tyr}$. To test the reproducibility of the measurements we performed the study twice in one patient. In both studies the measured enrichments were comparable notwithstanding different plasma Phe values at the start of the studies (Tables I and II).

The calculated rates of the in vivo hydroxylation of Phe into Tyr were 6.33 and $4.11 \mu \mathrm{mol} / \mathrm{kg}$ per hour in the two healthy individuals, being comparable to the values found by others using comparable methods $(8-10,16,17)$. Since the calculated hydroxylation rate of Phe into Tyr linearly depends on the enrichment of $\mathrm{L}-\left[\right.$ ring $\left.{ }_{-}^{2} \mathrm{H}_{4}\right] \mathrm{Tyr}$, the hydroxylation rates of Phe into Tyr were low in all patients, varying between 0.13 and $0.95 \mu \mathrm{mol} / \mathrm{kg}$ per hour (Table II). These hydroxylation rates are statistically significantly different from normal $(P<0.001)$. Next to this, within the studied group of patients with classical PKU the in vivo hydroxylation rate of patient 5 was statistically significantly different from the hydroxylation rate in the other patients $(P<0.01$; Table II). This difference in hydroxylation rate, however, did not result in a higher tolerance for dietary Phe in the patient. In the studied group of patients, no correlation was observed between the tolerance for Phe and the in vivo hydroxylation rate of Phe. At the studied plasma Phe concentrations, no relationship could be observed between the hydroxylation rate and the basal Phe concentration (Fig. 2). 


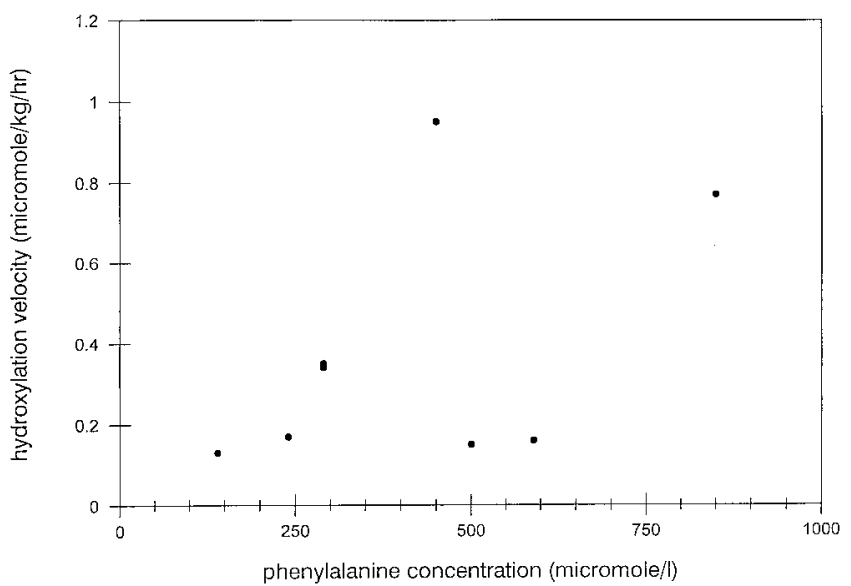

Figure 2. Relationship between plasma phenylalanine concentrations (micromole per liter) and hydroxylation in PKU patients (micromole per kilogram per hour).

\section{Discussion}

Thus far, it has been tacitly assumed that the estimation of the residual in vivo $\mathrm{PAH}$ activity directly relates to the empirically estimated tolerance for dietary Phe at $5 \mathrm{yr}$ of age. Using a bolus of oral L- $\left[1-{ }^{13} \mathrm{C}\right]$ Phe Treacy et al. (7) found no clear correlation between the oxidation rate of Phe and the dietary tolerance for Phe within a specific class of PAH-deficient patients, but quantitation of the in vivo Phe hydroxylation with this method is difficult. In this study, the relationship between the in vivo PAH activity and the tolerance for dietary Phe was tested by means of a primed continuous infusion of stable isotopically labeled tracers. This technique is validated in healthy humans $(8,9)$, and promises to present reliable estimates of the residual in vivo PAH activity in PKU patients. Using this method, Thompson and coworkers calculated normal in vivo hydroxylation rates in most PKU patients and 2 HPA patients (9-11), which is in disagreement with all other studies (4-7), and therefore cast doubt upon the applicability of this method to measure the hydroxylation rate in PKU and HPA patients.

In this study, first the method was re-evaluated in PKU patients before the relationship could be tested between the tolerance for dietary Phe and the in vivo hydroxylation of Phe into Tyr. We calculated several decreased hydroxylation rates in all our patients with classical PKU (Table II), which is in accordance with both in vitro and in vivo studies (4-7). The appropriateness of our measurements is underlined by the wash out studies in both the patient and control, while the reproducibility is shown by the similar hydroxylation rates when measured twice in the same patient (Table II).

While the results of the studies of Thompson and coworkers (9-11) and our study are different, part of the discussion must focus on differences with respect to the subjects, the strictness of dietary treatment, the test procedure, and the analysis of the isotopic enrichments, the calculations being exactly the same.

Concerning the studied patients, the ages at the time of the study in both of our studies show some overlap, while the severity of the PKU patients is comparable (9-11), although two of the other patients of Thompson et al. had HPA (9). One of the most striking differences is the strictness in dietary treat- ment. Most of Thompson and coworkers' patients were on a diet described as "relaxed strict dietary control" (9-11), some of them having intakes above the requirements advised in the recommended dietary allowances (19). In our study, six out of the seven studied patients were on a very strict dietary regimen. This difference in dietary Phe intakes resulted in differences in the actual plasma Phe concentrations between their study and our study-the patients of Thompson and coworkers (9-11) had higher Phe concentrations (mean Phe 1032 $\mu \mathrm{mol} / \mathrm{l}$, SEM $87 \mu \mathrm{mol} / \mathrm{l}$ ) than in our study (mean Phe 419 $\mu \mathrm{mol} / \mathrm{l}, \mathrm{SEM} 27 \mu \mathrm{mol} / \mathrm{l})$. Thompson et al. $(9,10)$ hypothesized that the normal hydroxylation rates in their studies were caused by high plasma Phe concentrations. However, neither their results nor ours showed evidence to support such a concentration dependency of the hydroxylation rate (Fig. 2; references 9-11).

Regarding the test procedure, differences exist in the protocol with respect to the amount and the type of the given isotopes. Compared with the studies of Thompson and coworkers (9-11), the continuous infusion of $\mathrm{L}-\left[\mathrm{ring}_{-}{ }^{2} \mathrm{H}_{5}\right] \mathrm{Phe}$ in our study was some 1.5 times higher to be able to measure the anticipated very low isotopic enrichments of Tyr with L-[ring${ }^{2} \mathrm{H}_{4}$ ] Tyr. With regards to the measurements of the turnover of Tyr, we used L- $\left[1{ }^{13} \mathrm{C}\right] \mathrm{Tyr}$, while Thompson and coworkers (9-11) used L- $\left[3,5-{ }^{2} \mathrm{H}_{2}\right]$ Tyr. Thompson and coworkers calculated turnover rates of Tyr in the patients which were about half the turnover reported in our study. The results in our patients are in line with the healthy adults of both our study and Clarke and Bier's study (8). This is important in view of equation 5 used to calculate the in vivo hydroxylation of Phe, in which the hydroxylation rate is proportional to the correction for the turnover of Tyr. Therefore, on the basis of the turnover rates, one would expect the hydroxylation rates in their studies to be lower than in our studies. In contrast, in our study the normal turnover of Tyr coincided with extremely low in vivo hydroxylation rates.

Concerning analytical differences between the studies of Thompson and coworkers (9-11) and our studies, it was already discussed that in our patients quantitation of the enrichments of $\mathrm{L}-\left[\mathrm{ring}_{-}{ }^{2} \mathrm{H}_{4}\right]$ Tyr using the method described by Thompson and Halliday (9) was difficult. However, the use of the method of de Jong et al. (15) allowed for the measurement of the extremely low enrichments of $\mathrm{L}-\left[\right.$ ring $\left._{-}{ }^{2} \mathrm{H}_{4}\right] \mathrm{Tyr}$ in our patients in a reliable way.

The results of our study showed that the in vivo hydroxylation of Phe may vary within the group of patients with classical PKU, but that this does not necessarily result in different tolerances, while different tolerances did not correlate with the in vivo hydroxylation rates within this studied group of patients with classical PKU.

A lack of correlation between the in vivo hydroxylation of Phe and the tolerance for Phe may be due to several causes. First, the investigated PKU patients may have shown too little heterogeneity to find a possible correlation. Other studies reported high correlations between the tolerance and both the in vitro mutation expression in cultured mammalian cells and the oxidation rate of $\mathrm{L}-\left[1-{ }^{13} \mathrm{C}\right] \mathrm{Phe}(7,20-22)$, but the groups of the patients ranged from the most severe form of PKU to the mildest form of HPA. If the data were re-analyzed for the group of patients with classical PKU, the results showed no correlation between the tolerance and the measured residual PAH activity $(7,20)$. 
Secondly, the tolerance for dietary Phe is the result of a combination of the in vivo hydroxylation rate, day to day variables, patient-dependent, and doctor-dependent factors. Dayto-day variables, such as intercurrent illness, energy and total protein intake, influence the balance between the catabolic and the anabolic state. Years ago, Güttler et al. (23) showed that the plasma Phe concentration rises during the night. This observation was confirmed by our studies showing that the Phe concentration rises during the night and during the morning if breakfast is omitted $(24,25)$. We reasoned that this effect is due to net protein catabolism (25). The patient-dependent variables include factors such as growth, and the compliance to the prescriptions, while the doctor-dependent variables include factors such as the prescribed amount of total protein, amino acid mixture (26) and energy, and the target Phe concentration (24). All these three causes, and a combination of all three, may explain the lack of correlation between the tolerance for Phe at $5 \mathrm{yr}$ of age and the in vivo hydroxylation rate of Phe in PKU patients in our study.

In conclusion, the results of this study showed that the primed-continuous infusion technique with stable isotopically labeled tracers is applicable in PKU patients and showed a clearly decreased in vivo conversion of Phe into Tyr in patients with classical PKU. The results of this study confirmed the results of in vitro and in vivo studies in PKU showing a decreased hydroxylation rate in PKU patients (4-7). The results of this study show that the defect in hydroxylation in these patients can be measured in vivo both by giving $\mathrm{L}-\left[1-{ }^{13} \mathrm{C}\right] \mathrm{Phe}$ and $\mathrm{L}-\left[\right.$ ring $\left.{ }^{2} \mathrm{H}_{5}\right] \mathrm{Phe}$. The results are in contrast with the normal hydroxylation rates of the studies of Thompson and coworkers (9-11). The different hydroxylation rates between their and our results can not be explained by differences in the patients or methods between their and our studies. In our study, a difference in hydroxylation rate was found in one of the patients with classical PKU compared with the others. No correlation was found between the tolerance for Phe at $5 \mathrm{yr}$ of age and the in vivo hydroxylation rate of Phe in patients with classical PKU. The results of this study, therefore, showed that within the group of patients with classical PKU, the difference in tolerance does not correlate with the in vivo hydroxylation. Further studies are necessary to explain the differences in results with the studies of Thompson and coworkers (9-11). In addition, further studies are necessary to investigate whether a correlation between the tolerance and the in vivo hydroxylation rate of Phe exists when patients are included with tolerances pointing at less severe forms of the PAH deficiency.

\section{Acknowledgments}

The authors express their gratitude to Mr. T. van Dijk, Mrs. M. van Rijn, Mrs. I. Mulder, Mr. T. de Jong, Mr. W. van Eck, and Dr. E.Th.H.G.J. Oremus for technical and dietary assistance, and preparing the solutions with the stable isotopes.

Financial support was obtained from the "Hendrik de Cock Stichting" from the University Hospital of Groningen and the "Stichting Erfelijkheidsvoorlichting."

\section{References}

1. Scriver, C.R., S. Kaufman, and S.L.C. Woo. 1995. The hyperphenylalaninemias. In The Metabolic Basis of Inherited Disease, 7th edition. C.R. Scriver, A.L. Beaudet, W.S. Sly, and D. Valle, editors. McGraw-Hill Inc., New York. 1015-1075.

2. Smith, I., and D.P. Brenton. 1995. Hyperphenylalaninaemias. In Inborn
Metabolic Diseases: Diagnosis and Treatment, 2nd edition. J. Fernandes, J.-M. Saudubray, and G. van den Berghe, editors. Springer-Verlag, Berlin. 47-60.

3. Güttler, F., and H. Lou. 1989 Phenylketonuria and hyperphenylalaninemia. Hyperphenylalaninaemias. In Inborn Metabolic Diseases: Diagnosis and Treatment, 1st edition. J. Fernandes, J.-M. Saudubray, and G. van den Berghe, editors. Springer-Verlag, Berlin. 161-174.

4. Trefz, F.K., T. Erlenmaier, D.H. Hunneman, K. Bartholome, and P. Lutz. 1979. Sensitive in vivo assay of the phenylalanine hydroxylating system with a small intravenous dose of heptadeutero L-phenylalanine using high pressure liquid chromatography and capillary gas chromatography/mass fragmentography. Clin. Chim. Acta. 99:211-220.

5. Bartholome, K., P. Lutz, and H. Bickel. 1975. Determination of phenylalanine hydroxylase activity in patients with phenylketonuria and hyperphenylalaninemia. Pediatr. Res. 9:899-903.

6. Blaskovics, M.E., G.E. Schaeffer, and S. Hack. 1974. Phenylalaninaemia. Differential diagnosis. Arch. Dis. Child. 49:835-843.

7. Treacy, E.P., J.J. Delente, G. Elkas, K. Carter, M. Lambert, P.J. Waters, and C.R. Scriver. 1997. Analysis of phenylalanine hydroxylase genotypes and hyperphenylalaninemia phenotypes using $\mathrm{L}-\left[1-{ }^{13} \mathrm{C}\right]$ phenylalanine oxidation rates in vivo: a pilot study. Pediatr. Res. 42:430-435.

8. Clarke, J.T.R., and D.M. Bier. 1982. The conversion of phenylalanine to tyrosine in man. Direct measurement by continuous intravenous tracer infusions of L-[ring- $\left.{ }^{2} \mathrm{H}_{5}\right]$-phenylalanine and $\mathrm{L}-\left[1-{ }^{13} \mathrm{C}\right]$-tyrosine in the postabsorptive state. Metabolism. 31:999-1005.

9. Thompson, G.N., and D. Halliday. 1990. Significant phenylalanine hydroxylation in vivo in patients with classical phenylketonuria. J. Clin. Invest. 86: 317-322.

10. Thompson, G.N., J.H. Walter, J.V. Leonard, and D. Halliday. 1990. In vivo enzyme activity in inborn errors of metabolism. Metabolism. 39:799-807.

11. Treacy, E., J.J. Pitt, K. Seller, G.N. Thompson, S. Ramus, and R.G.H Cotton. 1996. In-vivo disposal of phenylalanine in phenylketonuria: a study of two siblings. J. Inherited Metab. Dis. 19:595-602.

12. Güttler, F. 1980. Hyperphenylalaninemia. Diagnosis and classification of various types of phenylalanine hydroxylase deficiency in childhood. Acta Paediatr. Scand. 280:1-80.

13. Roede, M.J., and J.C. van Wieringen. 1985. Growth diagrams: Netherlands third nation-wide survey. Tijdschr. Soc. Gezondheidszorg. 63(Suppl.):1-34.

14. Wolfe, R.R. 1992. Radioactive and Stable Isotope Tracers in Biomedicine. Principles and Practice of Kinetic Analysis. Wiley-Liss, Inc. New York. $471 \mathrm{pp}$.

15. de Jong, A.P.J.M., R.M. Kok, C.A. Cramers, S.K. Wadman, and E. Haan. 1981. A new method for the determination of L-DOPA and 3- $O$-methyldopa in plasma and cerebrospinal fluid using gas chromatography and electron capture negative ion mass spectrometry. Clin. Chim. Acta. 171:50-62.

16. Marchini, J.S., L. Castillo, T.E. Chapman, J.A. Vogt, and V.R. Young. 1993. Phenylalanine conversion to tyrosine: comparative determination with L-[ring- $\left.{ }^{2} \mathrm{H}_{5}\right]$-phenylalanine and $\mathrm{L}-\left[1-{ }^{13} \mathrm{C}\right]$-tyrosine as tracers in man. Metabolism. 42:1316-1322.

17. Zello, G.A., L. Morai, A.S.F. Tung, R.O. Ball, and P.B. Pancharz. 1994 Plasma and urine enrichments following infusion of L- $\left[1-{ }^{13} \mathrm{C}\right]$-phenylalanine and $\mathrm{L}-\left[\right.$ ring- $\left.{ }^{2} \mathrm{H}_{5}\right]$-phenylalanine in humans: evidence of an isotope effect in renal tubular absorption. Metabolism. 43:487-491.

18. Krempf, M., A. Hoerr, and V.R. Young. 1990. Phenylalanine flux in adult men: estimates with different tracers and route of administration. Metabolism. 39:560-562.

19. National Research Council (U.S.) Subcommittee on the Tenth Edition of the RDAs. 1989. Recommended dietary allowances. National Academy Press, Washington, DC. 184 pp.

20. Okano, Y., R.C. Eisensmith, F. Güttler, U. Lichter-Konecki, D.S. Konecki, F.K. Trefz, M. Dasovich, T. Wang, K. Henriksen, H. Lou, and S.L.C. Woo. 1991. Molecular basis of phenotypic heterogeneity in phenylketonuria. $N$. Engl. J. Med. 324:1232-1238.

21. Eisensmith, R.C., D.R. Martinez, A.I. Kuzmin, A.A. Goltsov, A. Brown, R. Singh, L.J. Elsas, and S.L.C. Woo. 1996. Molecular basis of phenylketonuria and a correlation between genotype and phenotype in a heterogeneous Southeastern US population. Pediatrics. 97:512-516.

22. Svensson, E., U. von Dobeln, R.C. Eisensmith, L. Hagenfeldt, and S.L.C. Woo. 1993. Relation between genotype and phenotype in Swedish phenylketonuria and hyperphenylalaninemia patients. Eur. J. Pediatr. 152:132-139.

23. Güttler, F., E.S. Olesen, and E. Wamberg. 1968. Inverse diurnal variations of serum phenylalanine and tyrosine in phenylketonuric children on lowphenylalanine diet. In Proceedings of the 6th Symposium of the Society for the Study of Inborn Errors of Metabolism. J.D. Allan and K.S. Holt, editors. 149-158.

24. van Spronsen, F.J. 1996. Phenylketonuria: implications of some biochemical and clinical findings. Ph.D. thesis. University Hospital of Groningen, Groningen, The Netherlands. 159 pp.

25. van Spronsen, F.J., M. van Rijn, T. van Dijk, G.P.A. Smit, D.-J. Reijngoud, R. Berger, and H.S.A. Heymans. 1993. Plasma phenylalanine and tyrosine responses to different nutritional conditions (fasting/postprandial) in phenylketonuria: effect of sample timing. Pediatrics. 92:570-573.

26. Kindt, E., H.A. Lunde, L.R. Gjessing, S. Halvorsen, and S.O. Lie. 1988. Fasting plasma amino acid concentrations in PKU children on two different levels of protein intake. Acta Paediatr. Scand. 77:60-66. 